\title{
ST-elevation Myocardial Infarction and Multivessel Coronary Artery Disease - A Critical Review of Current Practice, Evidence and Meta-analyses
}

\author{
Filippo Figini, ${ }^{1}$ Shao Liang Chen² and Imad Sheiban' \\ 1. Division of Cardiology, Ospedale "Pederzoli", Peschiera del Garda, Italy; 2. Division of Cardiology, Nanjing Medical University, Nanjing, China
}

DOI: https://doi.org/10.17925/HI.2020.14.2.80

n recent years, practice and guidelines for patients with ST-elevation myocardial infarction (STEMI) have evolved from a 'culprit-only approach' to complete revascularisation; however, several issues remain, particularly regarding assessment of non-culprit lesions and timing of their revascularisation. Complete revascularisation should be performed in patients presenting with STEMI; however, available studies often present contradictory results regarding the optimal timing of non-culprit lesion percutaneous coronary intervention (PCI). The aim of this review is to provide a practical approach for the assessment of patients presenting with STEMI and multivessel coronary artery disease by analysing randomised trials, meta-analyses and our clinical experience. We recommend multivessel revascularisation at the time of primary PCI for simple cases, while we suggest deferring treatment of complex lesions; the optimal timing of staged PCI should be individualised according to clinical judgement.

\section{Keywords}

Acute myocardial infarction, coronary artery disease, primary $\mathrm{PCl}$ percutaneous coronary intervention

Disclosures: Filippo Figini, Shao Liang Chen and Imad Sheiban have no financial or non-financial relationships or activities to declare in relation to this article.

Review Process: Double-blind peer review.

Compliance with Ethics: This article involves a review of literature and does not report new clinical data, or any studies with human or animal subjects performed by any of the authors.

Authorship: The named authors meet the criteria of the International Committee of Medical Journal Editors for authorship for this manuscript, take responsibility for the integrity of the work as a whole and have given final approval for the version to be published.

Access: This article is freely accessible at touchCARDIO.com (c) Touch Medical Media 2021

Received: 15 October 2020

Accepted: 11 December 2020

Published Online: 22 February 2021

Citation: Heart International. 2020;14(2):80-5

Corresponding Author: Imad Sheiban, Ospedale Pederzoli, via Monte Baldo 24, 37019 Peschiera del Garda (VR), Italy. E: isheiban@ospedalepederzoli.it

Support: No funding was received for the publication of this article.
Reperfusion of infarct-related artery (IRA) in acute ST-elevation myocardial infarction (STEMI) is the procedure with the most clinical benefit in interventional cardiology. However, in around $50 \%$ of patients presenting with STEMI, other significant lesions are present, a finding which is associated to a worse prognosis. ${ }^{1,2}$ Most physicians performing primary percutaneous coronary intervention ( $\mathrm{PCl}$ ) have been trained according to a 'keep it as simple as possible' teaching, limiting the procedure to stent implantation on the culprit lesion only. ${ }^{3-5}$ This treatment paradigm was based on several considerations:

- acute myocardial infarction is associated with an inflammatory state that might predispose to acute stent thrombosis;

- platelet inhibition is often not complete because antiplatelet drugs have not reached their full level of activity (which can be partially reconsidered nowadays, as more potent and rapid antithrombotic drugs have become available);

- should a complication occur on a non-culprit vessel, this might cause an extensive ischaemic area and jeopardise haemodynamic stability;

- vasoconstriction is usually present during acute myocardial infarction, which might cause overestimation of other lesions and inadequate vessel sizing; ${ }^{6}$ and

- renal function and other comorbidities (e.g. significant anaemia) are often not known at the time of primary $\mathrm{PCl}$, when blood tests are generally not available; this concept must be kept in mind, as the population we are currently treating is getting older and more complex.

On the other hand, one could argue that instability might not be confined to the culprit lesion, but it can be related to a widespread process involving the whole coronary tree, so that other plaques might be predisposed to acute events. Indeed, several studies have questioned the traditional teaching of treating IRA only during primary $\mathrm{PCl}^{.8-14}$

In this review article, currently available trials and meta-analyses comparing IRA-only and multivessel revascularisation for patients with acute myocardial infarction and multivessel coronary artery disease are reviewed. A search was performed for the following keywords in the PubMed database: 'percutaneous coronary intervention', 'myocardial infarction' and 'multivessel'. We specifically focused on selection criteria and timing of revascularisation of non-culprit lesions. Five large randomised trials comparing IRA-only versus complete revascularisation were identified; details of these trials are summarised in Table 1.

\section{PRAMI trial}

In the PRAMI (Preventive Angioplasty in Acute Myocardial Infarction) trial, 465 patients were randomised to $\mathrm{PCl}$ on all lesions $\geq 50 \%$ during index procedure versus revascularisation of 
Table 1: Recent major randomised trials comparing IRA-only and multivessel revascularisation in patients with acute myocardial infarction and multivessel coronary artery disease

\begin{tabular}{|c|c|c|c|c|c|}
\hline Study & $\mathrm{N}$ & $\begin{array}{l}\text { Lesions } \\
\text { selection }\end{array}$ & Revascularisation strategies & Primary endpoint & Results* \\
\hline PRAMI ${ }^{10}$ & 465 & All lesions $\geq 50 \%$ & $\begin{array}{l}\text { - Complete revascularisation during primary } \\
\text { PCI } \\
\text { - IRA-only revascularisation (subsequent } \\
\text { stenting only in case of refractory angina } \\
\text { and objective evidence of inducible } \\
\text { ischaemia) }\end{array}$ & $\begin{array}{l}\text { Composite of death, } \mathrm{Ml} \text { and refractory } \\
\text { angina }\end{array}$ & $\begin{array}{l}\text { HR } 0.35 \text { (0.21-0.58), } \\
p<0.001\end{array}$ \\
\hline CVLPRIT ${ }^{11}$ & 296 & $\begin{array}{l}>70 \% \text { (or }>50 \% \\
\text { in two views) }\end{array}$ & $\begin{array}{l}\text { - } \text { Complete revascularisation (either during } \\
\text { primary PCl or staged within index } \\
\text { admission) } \\
\text { - IRA-only revascularisation }\end{array}$ & $\begin{array}{l}\text { Composite of death, Ml, heart failure } \\
\text { and ischaemia-driven revascularisation }\end{array}$ & $\begin{array}{l}\text { HR } 0.45(0.24-0.84), \\
p=0.009\end{array}$ \\
\hline DANAMI 3-PRIMULTII2 & 627 & $\begin{array}{l}>90 \% \text { or } 50-90 \% \\
\text { with FFR }<0.80\end{array}$ & $\begin{array}{l}\text { - Complete revascularisation within index } \\
\text { admission } \\
\text { - IRA-only revascularisation }\end{array}$ & $\begin{array}{l}\text { Composite of death, } \mathrm{Ml} \text { and } \\
\text { ischaemia-driven revascularisation }\end{array}$ & $\begin{array}{l}\text { HR } 0.56(0.38-0.83), \\
p=0.004\end{array}$ \\
\hline Compare-Acute ${ }^{13}$ & 885 & $\begin{array}{l}>50 \% \text { and FFR } \\
\leq 0.80\end{array}$ & $\begin{array}{l}\text { - Complete revascularisation within index } \\
\text { admission } \\
\text { - IRA-only revascularisation; subsequent } \\
\text { treatment left to clinical decision }\end{array}$ & $\begin{array}{l}\text { Composite of death, } \mathrm{MI} \text {, } \\
\text { ischaemia-driven revascularisation } \\
\text { and stroke }\end{array}$ & $\begin{array}{l}\text { HR } 0.35 \text { (0.22-0.55), } \\
p<0.001\end{array}$ \\
\hline COMPLETE $^{14}$ & 4,041 & $\begin{array}{l}\geq 70 \% \text { or } 50-70 \% \\
\text { with FFR } \leq 0.80\end{array}$ & $\begin{array}{l}\text { - Complete revascularisation performed } \\
\text { either during index hospitalisation or at a } \\
\text { later admission, within } 45 \text { days } \\
\text { - IRA-only PCl }\end{array}$ & Composite of death and $\mathrm{Ml}$ & $\begin{array}{l}\text { HR } 0.74(0.60-0.91), \\
p=0.004\end{array}$ \\
\hline
\end{tabular}

*HR in the complete revascularisation group $(95 \% \mathrm{Cl})$, $p$-value.

$\mathrm{Cl}=$ confidence interval; FFR = fractional flow reserve; $\mathrm{HR}=$ hazard ratio; IRA = infarct-related arteries; $\mathrm{MI}=$ myocardial infarction; $P C l=$ percutaneous coronary intervention .

IRA-only..$^{10}$ In patients undergoing IRA-only PCl, subsequent stenting of other lesions was discouraged unless refractory angina with objective evidence of inducible ischaemia was present. The study was prematurely stopped because of significantly lower incidence of the primary endpoint (death, myocardial infarction or refractory angina) in the multivessel $\mathrm{PCl}$ group; the comparison maintained statistical significance when the two hard endpoints (death and nonfatal myocardial infarction) were analysed.

\section{CvLPRIT trial}

The CVLPRIT (Complete versus Lesion-Only Primary PCI) trial confirmed the benefit of complete revascularisation in 296 patients with STEMI with multivessel disease.11 The primary endpoint (a composite of all-cause death, recurrent myocardial infarction, heart failure, and ischaemia-driven revascularisation within 12 months) occurred in $10.0 \%$ in the complete revascularisation group versus $21.2 \%$ in the IRA-only arm (hazard ratio [HR]: 0.45; 95\% confidence interval [Cl]: 0.24-0.84; $\mathrm{p}=0.009) .{ }^{11}$ In the complete revascularisation group, multivessel $\mathrm{PCl}$ was performed at the time of primary $\mathrm{PCl}$ in two-thirds of patients; in the remaining cases, based on operators' decision, revascularisation of non-culprit lesions was postponed to a staged procedure within the same hospitalisation. Patients treated with immediate multivessel PCI tended to have better results compared to staged procedure, although statistical significance was not reached and a selection bias can be hypothesised.

\section{DANAMI-3-PRIMULTI trial}

Angiographic appearance of non-culprit lesions might lead to overestimation of lesion severity and therefore to unnecessary stenting. However, there are theoretical concerns that fractional flow reserve (FFR) in acute myocardial infarction could not be reliable due to alterations in microcirculatory function and coronary flow. ${ }^{15}$ Ntalianis et al. validated the use of physiological assessment during myocardial infarction by performing FFR in 112 non-culprit lesions at time of primary PCl; the authors repeated the measurements at 1-month follow up, showing that FFR values remained consistent. ${ }^{16}$

The DANAMI-3-PRIMULTI (Complete Revascularisation versus Treatment of the Culprit Lesion Only in Patients with ST-Segment Elevation Myocardial Infarction and Multivessel Disease) study included 627 patients after successful IRA-only PCl; a strategy of FFR-guided complete revascularisation was compared to no further invasive treatment. ${ }^{12}$ Non-IRA PCI was performed before discharge. The primary endpoint of all-cause mortality, nonfatal myocardial infarction and ischaemia-driven revascularisation of lesions occurred in $13 \%$ of patients who had complete revascularisation versus $22 \%$ in the IRA-only PCl arm (HR: 0.56; 95\% Cl: 0.38-0.83; $p=0.004$ ). The benefit was, however, driven by a reduction in repeat revascularisation, an outcome that might be biased by the awareness that patients have one or more stenoses left untreated. Of note, $31 \%$ of non-IRA lesions evaluated with FFR were haemodynamically non-critical.

\section{Compare-Acute trial}

The Compare-Acute trial enrolled 885 patients with STEMI and multivessel disease; after IRA PCl, FFR was performed on all lesions of $>50 \%$ and patients were randomised 1:2 to complete revascularisation or medical therapy. ${ }^{13}$ The incidence of primary endpoint (death, myocardial infarction, revascularisation or stroke) was reduced in the complete revascularisation arm (HR: 0.35; 95\% Cl: 0.22-0.55; $\mathrm{p}<0.001$ ); again, the benefit was driven mainly by a reduction in the need for revascularisation at a later time point. In the complete revascularisation group, $\mathrm{PCl}$ of non-IRA lesions was performed during primary $\mathrm{PCl}$ procedure in $83 \%$ of cases, but could be deferred and staged within index hospitalisation, as in DANAMI-3 PRIMULTI. ${ }^{2}$ In the IRA-only group, subsequent management was left to the referring cardiologist's decision: in 59 patients in this arm elective $\mathrm{PCl}$ on non-IRA lesions was performed within 45 days 
after the index procedure, which was not counted as an adverse event. Another analysis of 36-month results of this trial confirmed the clinical benefit of FFR-guided complete revascularisation, which also reduced net healthcare-related costs. ${ }^{17}$

\section{COMPLETE trial}

The recently published COMPLETE (Complete versus Culprit-Only Revascularization Strategies to Treat Multivessel Disease after Early PCl for STEMI) trial is the largest randomised study on this topic, enrolling 4,041 patients randomised 1:1 to culprit-lesion only $\mathrm{PCl}$ or complete, staged revascularisation. ${ }^{14}$ Non-culprit lesions were considered significant either if $\geq 70 \%$ or if $\geq 50 \%$ with FFR $\leq 0.80$. In the complete revascularisation arm, according to operator's choice, non-culprit lesion treatment could be performed either during index hospitalisation or at a later admission, within 45 days. The primary endpoint of death or myocardial infarction occurred more frequently in the culprit lesion-only PCl group (10.5\% versus 7.8\%; HR: 0.74; 95\% Cl: 0.60-0.91; $\mathrm{p}=0.004$ ) and the benefit of complete revascularisation was consistent among patients undergoing complete revascularisation during the same admission or at a later time.

\section{Meta-analyses}

Elgendy et al. performed a meta-analysis comparing four different strategies: ${ }^{18}$ complete revascularisation at the time of index procedure, staged revascularisation before discharge, staged revascularisation at a second admission, and IRA-only revascularisation. Data on 2,285 patients from 10 trials were included (not comprising results from Compare-Acute and COMPLETE trials). Compared with a culprit-only approach, complete revascularisation (either immediate or staged) was associated with a lower risk of major adverse cardiac events due to a reduction in urgent revascularisation procedures; the rate of mortality or spontaneous myocardial infarction was comparable. No major differences in outcomes were found between immediate or staged complete revascularisation.

Another meta-analysis, published by Tarantini et al. in 2016, compared three different approaches: culprit-only $\mathrm{PCl}$, immediate complete revascularisation, and staged $\mathrm{PCl}$ (either during the same admission or after discharge)..$^{19}$ The authors concluded that staged multivessel revascularisation had superior outcomes in terms of mortality rate when compared both to immediate multivessel revascularisation and culprit-only $\mathrm{PCl}$. The benefit of staged $\mathrm{PCl}$ is particularly apparent in trials enrolling a high proportion of three-vessel disease and patients with diabetes.

In the same year, a critical review on this topic identified 25 meta-analyses comparing multivessel versus culprit-only $\mathrm{PCl}$ in STEMI; of those, 6 showed increased mortality after multivessel PCl, 10 were neutral and 9 found decreased mortality. ${ }^{20}$ The profound difference in results mainly depends on which studies were included in each paper and on statistical methodology. Bainey and colleagues recently published a meta-analysis on over 7,000 patients from 10 studies; complete revascularisation was associated with reduced cardiovascular mortality. The benefit was unchanged with FFR or angiography-guided strategies; also, no differences were found between an immediate or staged approach. ${ }^{21}$

\section{Multivessel disease in ST-elevation myocardial infarction and cardiogenic shock}

While in haemodynamically stable patients evidence moved from culprit-only to multivessel PCl, somewhat the opposite has occurred for
Figure 1: Examples of patients treated with immediate multivessel revascularisation
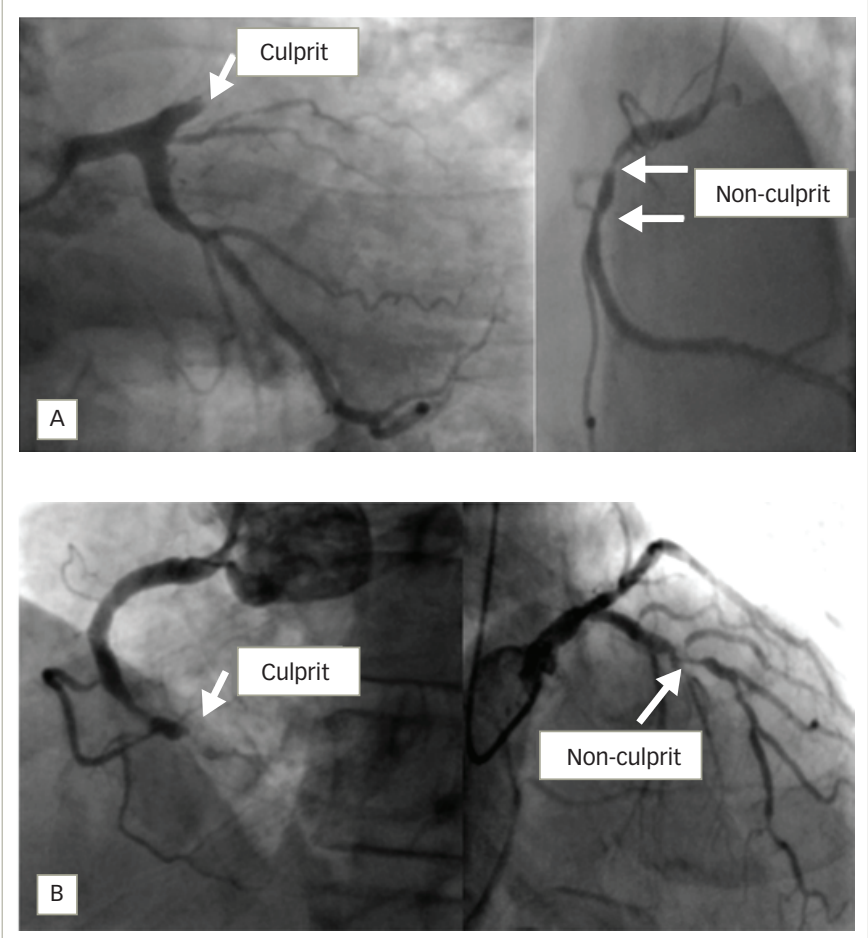

A: A 72-year-old male with diabetes presented with acute anterior STEMI, without haemodynamic instability. Angiography showed occluded proximal LAD artery (culprit lesion), $80 \%$ lesion in the mid-RCA, and non-significant (40\%) stenosis in a large obtuse marginal branch. During primary $P C l$, the $L A D$ and RCA were stented without complications. B: A previously healthy 64-year-old male patient presented with inferior STEMI. During primary PCI, after stent implantation on the RCA, percutaneous transluminal coronary angioplasty with one stent was performed on the mid-LAD artery. After discharge, echo stress testing was performed to assess the moderate disease on the LAD artery distal to the stent, showing no signs of residual inducible ischaemia.

$A D=$ left anterior descending; $P C l=$ percutaneous coronary intervention; $R C A$ = right coronary artery; STEMI = ST-elevation myocardial infarction.

patients presenting with acute myocardial infarction and cardiogenic shock. Indeed, the CULPRIT-SHOCK trial showed that a strategy of culprit-only $\mathrm{PCl}$, compared with multivessel primary $\mathrm{PCl}$ (on all lesions $270 \%$ ), was associated with a significant reduction in a composite of death and severe renal failure (45.9\% versus $55.4 \%$; relative risk 0.83; $95 \% \mathrm{Cl}: 0.71-0.96 ; \mathrm{p}=0.01$ ), mainly due to a mortality benefit. ${ }^{22}$ of note, subsequent staged revascularisation was encouraged in the culprit-only group, and performed in $17.7 \%$ of patients; a crossover rate of $12.5 \%$ occurred from culprit-only to immediate multivessel PCl, based on the operator's decision. According to this trial, revascularisation of non-culprit lesions during acute myocardial infarction presenting with cardiogenic shock was downgraded as a class III, level B indication in European Society of Cardiology guidelines..$^{23}$

\section{Discussion}

Taken together, available randomised data consistently suggest that, in haemodynamically stable patients, complete revascularisation is superior to culprit-artery revascularisation only. There are, however, two issues that are not completely clarified by the available evidence; these are, which non-culprit lesions should be revascularised and when should this be performed? Regarding the optimal timing of revascularisation on non-IRA lesions, an immediate multivessel procedure has the advantage of avoiding a second catheterisation, and could be preferable for patient comfort, risk of access-site bleeding and cost issues. However, deferring revascularisation of non-culprit lesions to a second procedure can give 

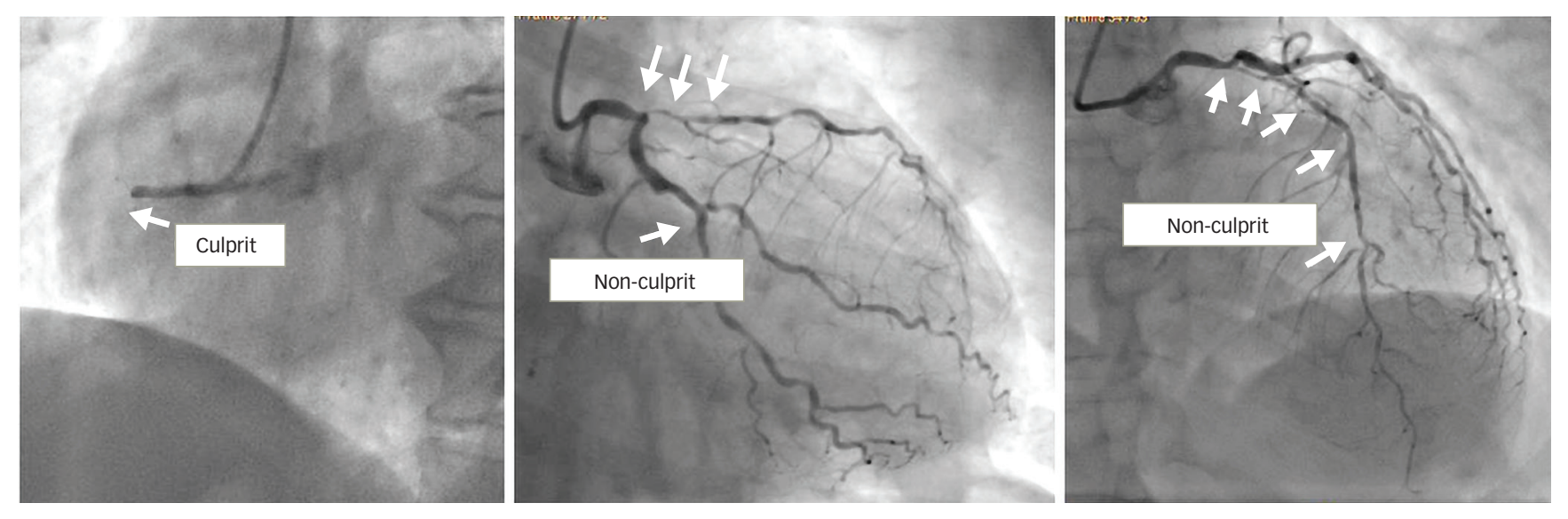

An 81-year-old male presented with inferior ST-elevation myocardial infarction and complex three-vessel disease, with a plaque involving distal left main and diffuse disease on the LAD artery. The patient remained haemodynamically stable throughout the procedure. In this case, after successful recanalisation of right coronary artery, we decided to defer treatment of non-culprit lesions. Considering the critical stenosis on the proximal LAD artery, staged procedure was performed before discharge. LAD = left anterior descending.

\section{Figure 3: A case of complex multivessel disease treated with deferred revascularisation}
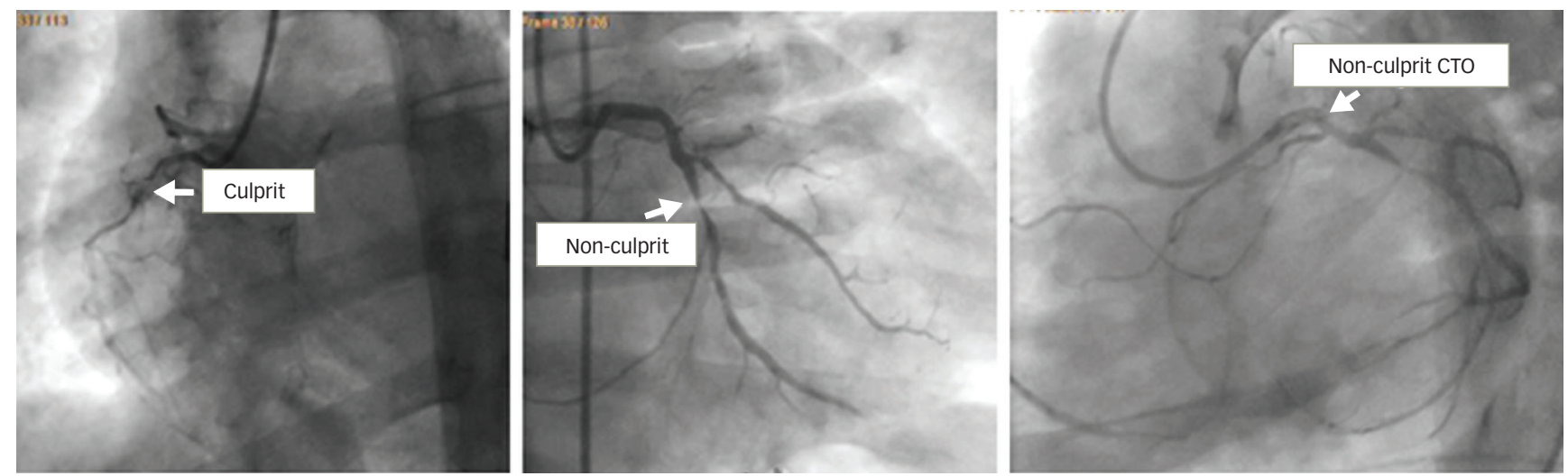

A 39-year-old male presented with acute inferior myocardial infarction and a chronically occluded LAD artery, percutaneous coronary intervention on the culprit lesion and left circumflex artery was performed during primary procedure. Following demonstration of viability in LAD territory, this artery was reopened during a second admission after 30 days. $C T O=$ chronic total occlusion; $L A D=$ left anterior descending

the advantages of overcoming the inflammation and vasoconstriction associated with the acute phase, it also allows for stable platelet inhibition and reduces the amount of contrast during primary $\mathrm{PCl}$, overcoming the concerns that traditionally discouraged multivessel revascularisation in STEMI. ${ }^{24}$

Should the operator decide on a staged procedure, it might be deferred to a second, elective admission, or if it could be performed during the same hospitalisation. The 2018 Guidelines on myocardial revascularisation from the European Society of Cardiology, based on a study design of the available trials, concluded that routine non-IRA revascularisation should be performed before hospital discharge, with a class Ila grade A recommendation. ${ }^{23}$ However, in the COMPLETE trial, a significant proportion of multivessel PCls were deferred to a second admission, with no apparent differences compared to in-hospital staged procedures. ${ }^{14}$ Moreover, data from a yet unpublished large registry suggest that the optimal window for revascularisation of non-culprit lesions might be between 10 and 28 days after primary PCl (Zhang et al., unpublished data).

We do believe that, when firm evidence from high-quality trials is lacking, the decision should be based on clinical judgement and individual physician's experience. Indeed, sophisticated statistical analyses, as pointed out in a paper by Bates et al.., ${ }^{20}$ can lead to support disparate conclusions, and mixing up results from different trials trying to identify a single approach for every situation inevitably blurs the characteristics of specific clinical settings.

Available evidence clearly suggests that complete revascularisation should be preferred to IRA-only $\mathrm{PCl}$; if the residual disease can be easily treated during primary $\mathrm{PCl}$ (i.e., one or two focal lesions on non-IRA vessel) and the patient is haemodynamically stable, this can be safely performed (as in the two examples shown in Figure 1). If instead, treatment of non-culprit stenoses requires a complex procedure (e.g. bifurcations, diffuse disease, chronic total occlusions, calcific plaques), it is advisable to schedule a second intervention (Figure 2). In our experience, as confirmed by results from COMPLETE trial, there is no significant risk in deferring revascularisation to a second admission, unless residual lesions have unstable angiographic features and/or involve the left main or proximal left anterior descending artery (Figure 3). The timing of staged PCI (before discharge or at a second admission) can, therefore, be left up to the operator's choice, taking into account angiographic appearance and location of lesions, renal function, risk of bleeding, local cost issues and the patient's 
Figure 4: Practical approach in primary transluminal coronary angioplasty in patients with acute myocardial infarction and multivessel coronary artery disease

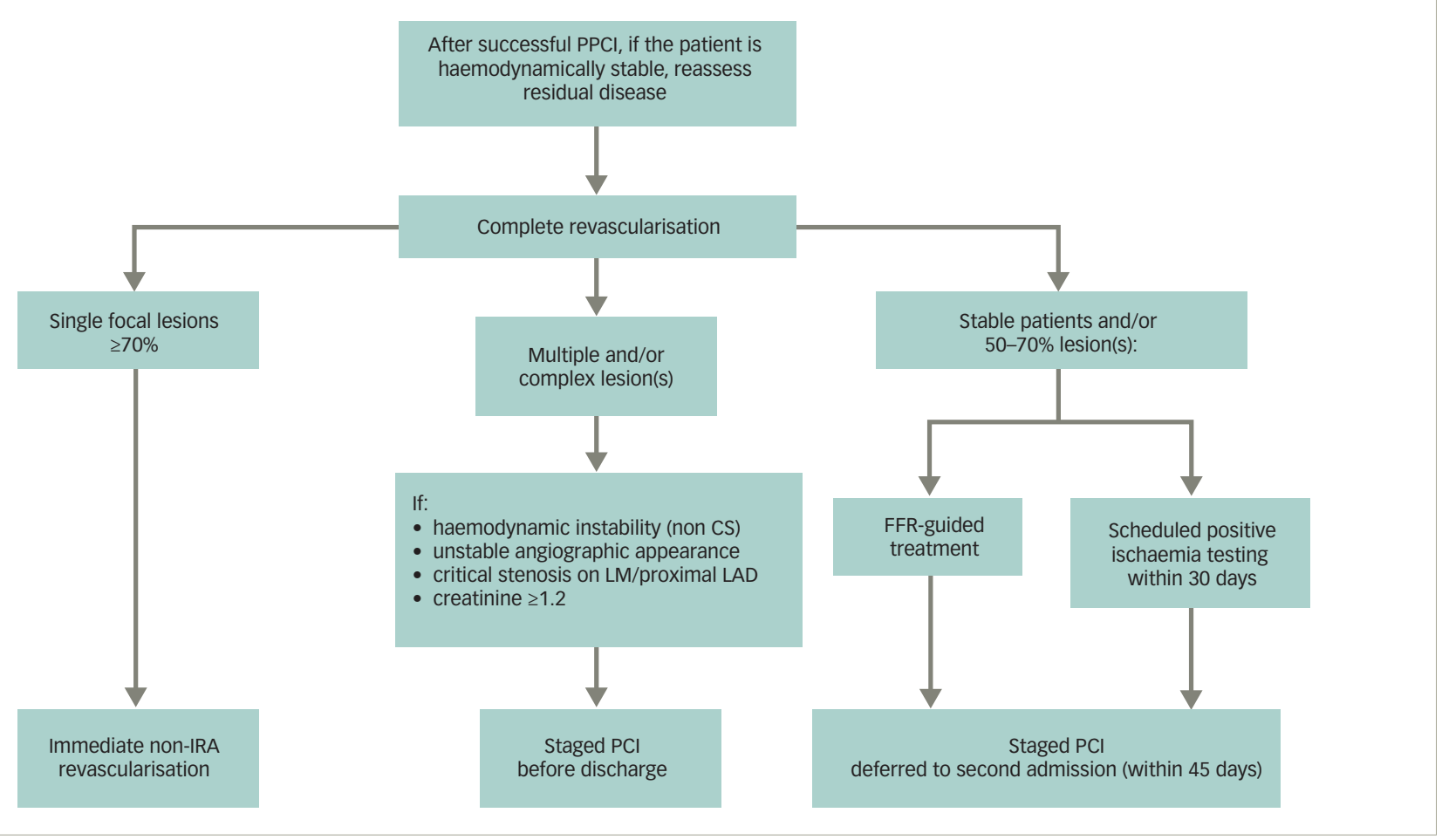

The flowchart presents our proposed approach to multivessel disease during ST-elevation myocardial infarction. Simple cases (with one or two focal non-culprit lesions) can be treated immediately. Other cases can be staged. In the presence of critical disease on the left-main and left-anterior descending artery and/or lesions with unstable angiographic features, we suggest to treat those stenoses before discharge; otherwise, we tend to schedule a second admission within 45 days. FFR can be used to assess intermediate lesions, particularly in complex situations and diffuse disease. Otherwise, when only lesions 50-70\% remain, non-invasive ischaemia testing can represent a valuable option. $C S=$ cardiogenic shock; $F F R=$ fractional flow reserve; $I R A=$ infarct-related arteries; $L A D=$ left anterior descending; $L M=l$ eft main; $P C I=$ percutaneous coronary intervention; $\mathrm{PPCl}=$ primary percutaneous coronary intervention

preferences. Our default approach is summarised in the flowchart presented in Figure 4.

The other unclear aspect is how to define which non-culprit lesions should be treated. Recent trials used different approaches, ranging from $\mathrm{PCl}$ on all stenoses $250 \%$ to routine FFR evaluation of all non-culprit lesions. In many physicians' minds, once the acute lesion has been fixed with primary $\mathrm{PCl}$, the residual coronary artery disease can be assessed and treated with the same approach we use for chronic coronary syndromes, which is the concept behind the traditional approach of IRA-only revascularisation.

The results from the above cited studies suggest that this assumption is not completely correct, probably because the process leading to clinical instability is not confined to culprit lesions only. Indeed, while recent data have questioned the utility of percutaneous revascularisation over medical therapy in stable angina, ${ }^{25,26}$ data from patients with acute myocardial infarction consistently show that complete revascularisation is associated with a reduced risk of hard endpoints. This reassures us that $\mathrm{PCl}$ has a beneficial effect on mortality and myocardial infarction, provided that it is performed in the appropriate clinical setting. Ideally, we should start to give more consideration to clinical presentation rather than percent stenosis. The same stenosis probably has very different prognostic implications (and therefore a different appropriate treatment) if it is discovered during primary $\mathrm{PCl}$ as a non-culprit lesion, or if it causes stable angina, or if it is 'incidentally' found after screening tests.

The DANAMI-3 PRIMULTI and Compare-Acute trials have shown that FFR guidance leads to underestimation of a significant proportion of lesions compared with angiographic evaluation, thereby reducing the need for stenting. However, we cannot exclude that part of the clinical benefit observed in the PRAMI and CVLPRIT trials might be due to treatment of lesions that were not currently causing significant ischaemia (and therefore could have been FFR-negative), but were unstable due to widespread inflammation. Indeed, intravascular ultrasound studies have shown that, compared with chronic coronary disease, in acute coronary syndromes, the incidence of unstable features is higher also in non-culprit lesions. ${ }^{27-29}$ Often, these lesions appear only moderately stenotic at angiography, in part due to positive vessel remodelling. This is consistent with the previous observation, reported over many years, that the extent of luminal narrowing is a poor predictor of subsequent acute events. ${ }^{30-32}$ On the other hand, intravascular ultrasound studies have failed to demonstrate the power of high-risk features in predicting future clinical events. ${ }^{33}$ As reported above, in a large meta-analysis, FFR-guided PCl, compared to angio-guided revascularisation, while associated with lower number of implanted stents, resulted equivalent in terms of event rate. ${ }^{21}$

Based on currently available evidence, the approach adopted in the COMPLETE trial appears sensible: $\mathrm{PCl}$ for lesions $\geq 70 \%$ and moderate stenoses with FFR $\leq 0.80 .{ }^{14}$ Considering the high cost of FFR, we tend, instead, to perform non-invasive ischaemia testing - within 30 days from index hospitalisation - in case of moderate residual lesions, particularly if they are located on non-prognostic segments.

Another unclear issue is whether the benefit of complete revascularisation after STEMI also applies to chronic total occlusions. Indeed, in the above-mentioned trials, chronic total occlusions were either excluded or present in a very small proportion of patients. One randomised trial, 
performed on 302 patients, has, however, failed to show a benefit of chronic total occlusion recanalisation after STEMI in terms of left ventricular ejection fraction or end-diastolic volume. ${ }^{34}$

\section{Conclusions}

Based on currently available data, we can state that, in haemodynamically stable patients presenting with acute myocardial infarction and multivessel disease, complete revascularisation should be considered the gold standard approach. In addition, non-IRA revascularisation can be safely deferred (either during index hospitalisation or scheduling a new admission within 45 days), particularly if a complex procedure is anticipated. Furthermore, FFR, instant wave-free ratio or non-invasive provocative tests are recommended for assessment of intermediate lesions.
1. Park DW, Clare RM, Schulte PJ, et al. Extent, location, and clinical significance of non-infarct-related coronary artery disease among patients with ST-elevation myocardial infarction JAMA. 2014;312:2019-27.

2. Sorajja P, Gersh BJ, Cox DA, et al. Impact of multivessel disease on reperfusion success and clinical outcomes in patients undergoing primary percutaneous coronary intervention for acute myocardial infarction. Eur Heart J. 2007;28:1709-16.

3. Toma M, Buller CE, Westerhout CM, et al. Non-culprit coronary artery percutaneous coronary intervention during acute ST-segment elevation myocardial infarction: insights from the APEX-AMI trial. Eur Heart J. 2010;31:1701-7.

4. Widimsky P, Holmes DR, Jr. How to treat patients with ST-elevation acute myocardial infarction and multi-vessel ST-elevation acute myocardial infarction

5. Kornowski R, Mehran R, Dangas G, et al. Prognostic impact of staged versus "one-time" multivessel percutaneous intervention in acute myocardial infarction: analysis from the HORIZONS-AMI (harmonizing outcomes with revascularization and stents in acute myocardial infarction) trial. J Am Coll Cardiol. 2011;58:704-11.

6. Hanratty $\mathrm{CG}$, Koyama Y, Rasmussen $\mathrm{HH}$, et al. Exaggeration of nonculprit stenosis severity during acute myocardial infarction: implications for immediate multivessel revascularization. J Am Coll Cardiol. 2002;40:911-6.

7. Goldstein JA, Demetriou D, Grines $\mathrm{CL}$, et al. Multiple complex coronary plaques in patients with acute myocardial infarction. N Eng/ I Med. 2000:343:915-22.

8. Di Mario C, Mara S, Flavio A, et al. Single vs multivessel treatment during primary angioplasty: results of the multicentre randomised HEpacoat for cuLPrit or multivessel stenting for Acute Myocardial Infarction (HELP AMI) Study. Int I CardiovasC Intervent. 2004;6:128-33.

9. Politi L, Sgura F, Rossi R, et al. A randomised trial of target-vessel versus multi-vessel revascularisation in ST-elevation myocardial infarction: major adverse cardiac events during long-term follow-up. Heart. 2010;96:662-7.

10. Wald DS, Morris JK, Wald NJ, et al. Randomized trial of preventive angioplasty in myocardial infarction. N Eng/ J Med. 2013;369:1115-23.

11. Gershlick AH, Khan JN, Kelly DJ, et al. Randomized trial of complete versus lesion-only revascularization in patients undergoing primary percutaneous coronary intervention for STEMI and multivessel disease: the CVLPRIT trial. JAm Coll Cardiol 2015:65:963-72

12. Engstrom T, Kelbaek $H$, Helqvist S, et al. Complete revascularisation versus treatment of the culprit lesion only in patients with ST-segment elevation myocardial infarction and multivessel disease (DANAMI-3-PRIMULTI): an open-label, randomised controlled trial. Lancet. 2015;386:665-71.

13. Smits PC, Abdel-Wahab M, Neumann FJ, et al. Fractional flow reserve-guided multivessel angioplasty in myocardial infarction. N Engl J Med. 2017;376:1234-44.

14. Mehta SR, Wood DA, Storey RF, et al. Complete revascularization with multivessel $\mathrm{PCl}$ for myocardial infarction. N Engl J Med. 2019;381:1411-21.

15. Gibson CM, Ryan KA, Murphy SA, et al. Impaired coronary blood flow in nonculprit arteries in the setting of acute myocardial infarction. The TIMI Study Group. Thrombolysis in myocardial infarction. The TIMI Study Group. Thrombolysis in

16. Ntalianis A, Sels JW, Davidavicius G, et al. Fractional flow reserve for the assessment of nonculprit coronary artery stenoses in patients with acute myocardial infarction. JACC Cardiovas Interv. 2010;3:1274-81.

17. Smits PC, Laforgia PL, Abdel-Wahab M, et al. Fractional flow reserve-guided multivessel angioplasty in myocardial infarction: 3-year follow-up with cost benefit analysis of the compareAcute trial. Eurolntervention. 2020;16:225-32.

18. Elgendy IY, Mahmoud AN, Kumbhani DJ, et al. Complete or culprit-only revascularization for patients with multivessel coronary artery disease undergoing percutaneous coronary intervention: a pairwise and network meta-analysis of randomized trials. JACC Cardiovasc Interv. 2017;10:315-24.

19. Tarantini G, D'Amico G, Brener SJ, et al. Survival after varying revascularization strategies in patients with ST-segment elevation myocardial infarction and multivessel coronary artery disease: a pairwise and network meta-analysis. JACC Cardiovasc Interv. 2016;9:1765-76.

20. Bates ER, Tamis-Holland JE, Bittl JA, et al. PCI strategies in patients with ST-segment elevation myocardial infarction and multivessel coronary artery disease. I Am Coll Cardiol. 2016;68:1066-81.

21. Bainey KR, Engstrom T, Smits PC et al. Complete vs culprit-lesion-only revascularization for ST-segment elevation myocardial infarction: a systematic review and meta-analysis. JAMA Cardiol. 2020;5:1-9.

22. Thiele H, Akin I, Sandri M, et al. PCl strategies in patients with acute myocardial infarction and cardiogenic shock. N Eng/ J Med. 2017;377:2419-32.

23. Neumann FJ, Sousa-Uva M, AhIsson A, et al. 2018 ESC/EACTS guidelines on myocardial revascularization. Eurolntervention. 2019:14:1435-534
24. Ahn KT, Oh JK, Seong SW, et al. One-year clinical outcomes between single- versus multi-staged PCI for ST elevation myocardial infarction with multi-vessel coronary artery disease: from Korea Acute Myocardial Infarction Registry-National Institute of Health (KAMIR-NIH). Korean Circ J. 2020;50:220-33.

25. Al-Lamee R, Thompson D, Dehbi HM, et al. Percutaneous coronary intervention in stable angina (ORBITA): a double-blind, randomised controlled trial. Lancet. 2018;391:31-40.

26. Maron DJ, Hochman JS, Reynolds HR, et al. Initial invasive or conservative strategy for stable coronary disease. N Eng/ J Med. 2020;382:1395-407.

27. Laimoud M, Faris F, Elghawaby H. Coronary atherosclerotic plaque vulnerability rather than stenosis predisposes to non-ST elevation acute coronary syndromes. Cardiol Res Pract. 2019;2019:2642740

28. Pundziute G, Schuijf JD, Jukema JW, et al. Evaluation of plaque characteristics in acute coronary syndromes: non-invasive assessment with multi-slice computed tomography and invasive evaluation with intravascular ultrasound radiofrequency data analysis. Eur Heart J. 2008;29:2373-81

29. Rodriguez-Granillo GA, MCFadden EP, Valgimigli M, et al. Coronary plaque composition of nonculprit lesions, assessed by in vivo intracoronary ultrasound radio frequency data analysis, is related to clinical presentation. Am Heart 1 2006;151:1020-4.

30. Ghaffari S, Erfanparast S, Separham A, et al. The relationship between coronary artery movement type and stenosis severity with acute myocardial infarction. J Cardiovasc Thorac Res. 2013:5:41-4.

31. Giroud $D, L i$ JM, Urban $P$, et al. Relation of the site of acute myocardial infarction to the most severe coronary arterial stenosis at prior angiography. Am J Cardiol. 1992;69:729-32.

32. Little WC, Constantinescu M, Applegate RJ, et al. Can coronary angiography predict the site of a subsequent myocardial infarction in patients with mild-to-moderate coronary artery disease? Circulation. 1988;78:1157-66.

33. Stone PH, Saito S, Takahashi S, et al. Prediction of progression of coronary artery disease and clinical outcomes using vascular profiling of endothelial shear stress and arteria plaque characteristics: the PREDICTION Study. Circulation. 2012;126:172-81.

34. Henriques JP, Hoebers $L P$, Ramunddal $T$, et al. Percutaneous intervention for concurrent chronic total occlusions in patients with STEMI: The EXPLORE Trial. J Am Coll Cardiol. 2016;68:1622-32 